\title{
Students' Perception on Learning Vocabulary through WhatsApp Group Media During Covid-19 Pandemic
}

\author{
Tyas Aina Yuskandina \\ tyas.aina17174@student.unsika.ac.id \\ Yuna Tresna Wahyuna \\ yuna.tresna@fkip.unsika.ac.id \\ Sumarta \\ litcomnet@yahoo.co.id

\section{Universitas Singaperbangsa Karawang}

\begin{abstract}
Social networking apps have emerged as potentially useful new tools for improving second language vocabulary acquisition. The current research compares the growth of academic vocabulary knowledge in English. The purpose of this study is to compare the perspectives or views of the Department of English Education at Singaperbangsa Karawang University (UNSIKA). Online learning conducted during the Covid-19 Pandemic students using WhatsApp group media to traditional vocabulary instruction methods. The qualitative research method used in this study is a descriptive design with an explanation of the form of narrative related to the views of students in online learning during the pandemic. Data was collected through interviews specially semi structure interview based on interview guideline and data analysis by involving three students in the online learning process. The findings provide information about the learning process as well as the advantages and disadvantages of WhatsApp media. The interview results show that students in general have a positive attitude toward learning vocabulary through WhatsApp group media. However, technological limitations, unfamiliar presentation, and learning activities may prevent students from participating in a WhatsApp media lesson.
\end{abstract}

Keywords: Students' Perceptions; Vocabulary Online Learning; WhatsApp Group

\section{INTRODUCTION}

The Coronavirus Pandemic has had an impact not only on human life, but also on medical education and residency training all over the world. Due to the ongoing COVID 19 pandemic, all face-to-face classes were halted through the use of social distancing principles. Every day, because of the implications for our students, an online teaching session was held. The students used WhatsApp group media for online learning, which allows for groups of an unlimited number of students, but video calls and calling only allow for 5 to 8 students. Students' perspectives were 
gathered at the end of online learning. Due to the difficulty of preventing the outbreak from spreading further, world leaders have devised extremely stringent rules to break the chain of COVID-19 spread.

Some of the World Health Organization's (2019) recommended standards, such as social and physical distancing, have made implementation difficult for each country. In March 2020, Indonesia implemented "large-scale social restrictions" in response to the growing number of people infected with COVID-19. These were followed by additional regulations such as employees working from home, praying from home, and students from early childhood education to higher education homeschooling (Regulation of Indonesian Government No.21, 2020, 2020). Online learning can be effective in digitally advanced countries (Basilaia \& Kvavadze (2020), but it is ineffective in Indonesia. However, in Indonesia, much of the learning and teaching, as well as the administrative activities of academic institutions, is done by hand (Salam, S., Jianqiu, Z., Pathan, Z. H., \& Lei, n.d.)

Students who access the internet via smartphones are unable to benefit from online learning because a large portion of online content is not accessible via WhatsApp media. Changes in educational systems necessitate the implementation of distance education or online learning. Learning, e-learning, distance education, correspondence education, external studies, and flexibility are all terms used to describe the process of learning. Massive open online courses (and learning. In the same conditions and rules apply. The United States E-learning, according to the Centers for Disease Control and Prevention (2020), Plans have been put in place, including digital and distance learning options where possible. Appropriate to ensure student education continuity during the COVID-19 pandemic. According to studies on students' perceptions of WhatsApp for teaching and learning vocabulary, the use of mobile phones contributes to positive attitudes toward fostering learner autonomy encouraging collaboration and increasing motivation for specific academic goals (Arifani, 2019);(Bere, 2013);(Dehghan, F., Rezvani, R., \& Fazeli, 2017), et al., 2017;(Fathy et al., 2015) ; (Lu, 2008) (Binti Mistar, I., \& Embi, n.d.) and Zulkanain et al. (2020) note that WhatsApp is a virtual platform for students' needs in Malaysia, a neighboring country to Indonesia.

\section{LITERATURE REVIEW}

\section{Previous Study}

According to (Stockwell, 2008) research, even when the material is adapted to their mobile phones, when given the option of using a mobile phone or personal to complete word learning activities, the majority of students choose personal via WhatsApp media. The goal of this study is to see if there are any features associated with completing activities on the mobile platform WhatsApp that might influence students' decisions to use their personal phones instead of their cell phones. Work they achieve higher scores with personal so choose to use instead, do students find that activities on mobile that take too long to complete 


\section{Online Learning Vocabulary}

Vocabulary is inextricably linked to the success of learning a foreign language. All four language skills, listening, speaking, reading, and writing, are made up of and involve a collection of words that form a unified meaning. Anyone with a large vocabulary storage capacity will undoubtedly outperform those with fewer. Unfortunately, students from non-English speaking countries have a dearth of vocabulary mastery. Online learning focuses on Internet-based courses that are available both synchronously and asynchronously. Synchronous learning is a type of learning that involves direct interactions between students and teachers while also utilizing online forms of communication such as conferences and online learning via WhatsApp media.

WhatsApp group as language learning platform, has become one of the most popular social-networking apps on mobile phones and computers (Yeboah, J., \& Ewur, 2014). It enables users to send each other free messages over the Internet Users can also send pictures, audio files, and videos to one another. WhatsApp allows you to create a group of users who can communicate with one another. Many instructors have chosen WhatsApp as a platform for students to receive and submit vocabulary learning assignments. WhatsApp assists instructors in saving time (Lauricella \& Kay, 2013) better managing the classroom, and keeping students up to date on classroom activities (Awada, 2016). WhatsApp promotes active learning and the development of high communicative expectations (Pratama \& Kartikawati, 2017) Rambe \& Bere, 2013). Other WhatsApp functions include peer communication (Bouhnik et al., 2014) and fostering interaction between students and instructors (Lents, 2015)

WhatsApp and vocabulary learning, many studies investigated the impact of Short Message Service (SMS), a basic feature of mobile phones, on vocabulary learning prior to the widespread use of smartphones and the rapid use of social networking applications such as WhatsApp. These studies focused on various aspects of vocabulary, such as idioms (Hayati et al., 2013) and English collocations (Motallebzadeh, Beh-Afarin \& Daliry Rad, 2011). The majority of studies that compared the use of SMS in vocabulary learning to traditional methods found positive results e.g.,(Alemi et al., 2012); Cavus \& Ibrahim, 2009; Lu, 2008; Song, 2008; Thornton \& Houser, 2001; Zhang, et al.,2011). They have difficulty understanding and communicating information. As a result, the majority of them are unable to pursue global opportunities or challenges because they continue to struggle with language barriers, whereas others do not. WhatsApp has recently surpassed Facebook as the most popular app on a user's smartphone or computer. It connects everyone, whether they are individuals or groups, in real time. Almost all teachers and students now use the application on a daily basis and with frequency. People now use Whatsaap to communicate, which has become a societal trend. This situation should be viewed as a fantastic opportunity to accelerate the adoption of online learning in the classroom. This is to demonstrate the significance of 
vocabulary in the development of a language. Furthermore, one could argue that the most important aspect of a language is its vocabulary. Sadenova et al. (2017) agreed with Harmer that vocabulary is one of the foundations of language.

Smartphone as learning tools, The rapid development of mobile technologies such as mobile phones and handheld computers has aided MALL Mobile-assisted language learning (MALL) has reached new heights (Georgia, 2020). Early attempts to use mobile phones in education were not particularly successful due to significant drawbacks associated with mobile device technology. Learners complained about the screen size of their mobile phones (Hayati et al, 2013), battery drain, a complicated keyboard (Kim, Rueckert, Kim, \& Seo, 2013), and limited storage capacity (Zhang, Song, \& Burston, 2011). However, with the popularity of smartphones, which have largely replaced mobile phones, those issues are resolved. Smartphones today have larger, higher-resolution screens, as well as a visual keyboard. They have a high processing speed, which makes navigation simple and smooth.

\section{METHOD}

\section{Design And Sample}

This study uses a qualitative method with descriptive design involving three students of the Department of English Education at Singaperbangsa Karawang University (UNSIKA). This research instrument included a semi-structured interview and data analysis. Because the situation and conditions did not allow for direct physical contact, the researchers collected data through online interviews. Semi-structured interviews are flexible in nature, allowing new topics to be raised during the interview and determining how English students perceive online learning during the Covid-19 pandemic. COVID-19, like many other aspects of daily life, has undoubtedly had a significant impact on students, instructors, and educational organizations all over the world (Mailizar, Almanthari, Maulina, \& Bruce, 2020). The pandemic forced schools, colleges, and universities all over the world to close their doors so that students could practice social distancing (Toquero, 2020). Having said that, moving efficiently from a traditional education environment to distance and virtual learning could not happen overnight. At this point, the rapid transformation is associated with a number of obstacles and challenges (Crawford, Butler-Henderson, Rudolph, \& Glowatz, 2020). However, because no one knows when this pandemic will be completely eradicated, educational institutions around the world decided to use the already available technical resources to create online learning material for students of all academic fields (Kaur, 2020).

\section{Instrument and Procedure}

This research used a semi structured interview with three participants chosen specifically by the researcher. The semi structured interview gained insightful answers towards 4 questions made by the researcher, in order the research by 
(Bensalem, 2018). the instrument used in this research provide an interview guideline design by the researcher, to provide insightful answer related with the research.

\section{Data Analysis}

Thematic analysis will be used to analyse the research data. (Braun et al., 2008) in an effort to simplify the approach to Thematic analysis as a method of qualitative data analysis, define thematic analysis as a process of identifying themes or patterns with the sole purpose of generating meaning within raw qualitative data. They argue that it is the fundamental skill that must be learned because it provides insights into many other types of qualitative analyses (Braun \& Clarke, 2006). As Braun and Clarke continue to argue, thematic analysis is a method that, unlike other popular approaches such as content analysis, is flexible and can be used across different epistemological approaches.

\section{RESULT AND DISCUSSION}

Following the interview, the results show that there are both positive and negative opinions about online learning, such as learning vocabulary through WhatsApp media. Students stated that online vocabulary via WhatsApp was less effective and more effective due to a variety of factors, including: the material presented being difficult to understand in deliver materials, and another thing for students and lectures. Furthermore, online learning appears to be boring and impeding the right conditions in this Covid 19- Pandemic where everything is done online and not everyone responds quickly when discussing vocabulary, it is sometimes difficult to know the opponent's expression in this discussion, and usually the network does not support, and so on.

The advance the technology indicates several applications online during Covid 19 Pandemic, WhatsApp become the most crucial application for teacher, to teach online learnings. Based on statement from the participants state that

"Online learning is currently the best option because the Covid-19 pandemic situation is not an impediment to learning vocabulary, even though WhatsApp, which has a variety of but limited features for learning delivery"

This online learning is the appropriate target, because in the Covid-19 situation, this is not an impediment to learning vocabulary through WhatsApp. Based on statement from the participants state that

"This online learning is the right target because it avoids the covid 19 pandemic disease, plus it has many shortcomings and advantages, but the network is less stable, but an advantage of the network is that WhatsApp is more efficient and basic because almost everyone has WhatsApp application and can learn through WhatApp group. It is effective in all features such as image, video, and recording in the WhatsApp group" 
WhatsApp is an easy way to develop vocabulary because it has features that are simple to understand and can aid in the learning process but the capacity to limited large. Based on statement form the participant state that

"It is quite effective for developing vocabulary because through WhatsApp we can communicate easily in either English or Indonesian, we can learn new vocabulary because we have to type messages in English, for the features it can send audio, it is sufficient to use it, but the capacity is not too large. However, the audio exposure is quite clear, the application can be used for audio in listening learning, etc".

Regarding to the vocabulary collection WhatsApp hold the usefulness because it provides some information or subject that the lecturers send via message for voice note, as this state in the quotation below

"In my opinion, very useful for vocabulary collection. Because the lecturers are also on campus, audio is sent to WhatsApp if the listening subject prefers it.

Because of the adaptation to the current Covid 19-Pandemic, WhatsApp is the most accessible and user-friendly application."

Because most people now have WhatsApp, the benefits stated by students indicate that it is the right application at this time for lecturers or teachers to use when teaching. Based on statement below:

"It is effectiveness sometimes is present or not, but referring to the features of

WhatsApp itself, it is not effective because the lecturer usually prefers to do assignments or questions through photos or recordings, so students cannot discuss optimally, so they prefer to use other applications such as zoom meeting or google meet so that lecturers can deliver the material well and easily to unify."

During a pandemic, effective use of WhatsApp group can reduce online learning, which means that by using this WhatsApp, you can take advantage of existing features. Based on statement below

"I think is effective because WhatsApp oppress many futures that could provide me with any kind of sending file, message and voice note"

However, the accessibility of WhatsApp group that could easily use any time we want the participant preferred this apps that any other acts as this state by the statement

"Because the WhatsApp feature is easily accessible from anywhere and at any time, if you don't understand, you usually ask a friend or use a translation tool." 
On the other hand, the increase of the vocabulary towards the student happened to be revealed in the process of communication between the students and lecture in English language, the statement say that

"After conducting group discussions on WhatsApp group tool, itself can increase vocabulary in the learning process by switching the language from English to Indonesia and as well as the opposite that occurs with the lecturer."

During the Covid 19 pandemic, you can interact between students and lecturers by using WhatsApp group while learning, which means it does not become an impediment even though there are some restrictions. Based on statement below

"The benefit of applications for online learning, such as this pandemic, is that they can facilitate interaction between lecturers and students like me because we can send messages quickly and I don't encounter many obstacles when sending documents using the WhatsApp application."

The learning done by students and teachers demonstrates that there is diversity when dealing with online learning with different situations of students in understanding vocabulary state by the statement

"Sometimes online learning via WhatsApp makes you bored, but another way to avoid boredom is to make it happy and intercut with discussions between friends, making it appear more enjoyable when learning takes place".

The learning process during covid 19 pandemic there are advantages and disadvantages because online learning still considers as a new learning method which apply during this time therefore, students try to find out how the online learning not bored for them, based on the statement below

"More to the study list, and we know how long our study hours are interlaced with music, watching more YouTube to be more disciplined, and occasionally looking for more varied places and situations to get positive vibes."

Because of impossibility of learning activities due to the covid 19 pandemic, students are also required to study in pleasant conditions. Based on the statement below

"Online learning during this pandemic is undoubtedly very boring because there

are few interactions when online learning, and socialization with friends is

reduced by eliminating group work; thus, to overcome the boredom of online learning, I actively participate in other activities such as watching YouTube and looking for games. English in other contexts"

Have a positive attitude toward the use of WhatsApp for vocabulary learning In fact, $90 \%$ of participants thought that learning new words through WhatsApp was 
a fun way to learn. Despite the fact that both have advantages and disadvantages in using WhatsApp, three respondents are eager to discuss new vocabulary.

In discussion part, so even though WhatsApp group has helped students construct their vocabulary knowledge, this study lends support to the constructivist theory. The evidence for WhatsApp's utility backs up the findings of Fageeh (2013), who conducted his study in a similar educational setting, and other researchers (Lawrence, 2014; Basal et al., 2016). WhatsApp is a tool that is most often used in the course of learning activities or other activities that can be used as a mode of interaction to facilitate discussions and other important things. The current study's discussion also highlights the participants' positive attitudes toward using WhatsApp group to learn new vocabulary are consistent with those reported by previous studies, such as Alhadhrami (2016), who surveyed Arab EFL students in Oman. WhatsApp was regarded the most useful app for English language learning through his participants. As can be seen from the use of WhatsApp, which has limited advantages and disadvantages, WhatsApp is used as a communication tool for the interconnection of information between lecturers and students, that the effectiveness used when learning vocabulary through WhatsApp is significant.

\section{CONCLUSION}

Online learning is the best thing for students at Singaperbangsa Karawang University (UNSIKA) to do in order to reduce and break the chain of spread of the Covid-19 Pandemic. The findings of this study indicate that students' diverse perceptions of online learning in this pandemic era have various positive and negative perceptions explained by participants. So, based on the data obtained, it can be concluded that important supporting factors, such as a good internet connection and the use of effective online learning media, as well as supporting facilities by using WhatsApp group as an easy-to-use alternative, as well as good learning methods and strategies in increasing student learning motivation, are required to obtain a good online learning about vocabulary learning. The findings of this study can be used as a reference for educators, lecturers, schools, and other institutions to easily improve and perfect student teaching because we can add vocabulary in learning delivered by lecturers and also improve the quality of online learning by using WhatsApp.

\section{REFERENCES}

Alemi, M., Reza, M., Sarab, A., \& Lari, Z. (2012). Successful Learning of Academic Word List via MALL: Mobile Assisted Language Learning. 5(6), 99-109. https://doi.org/10.5539/ies.v5n6p99

Arifani, Y. (2019). The application of small WhatsApp groups and the individual flipped instruction model to boost EFL learners' mastery of collocation. CALL-EJ, CALL-EJ, 2((1)), 52-73.

Awada, G. (2016). Effect of whatsapp on critique writing proficiency and perceptions toward learning. Cogent Education, 3(1), 1-25. 
https://doi.org/10.1080/2331186X.2016.1264173

Bensalem, E. (2018). The Impact of WhatsApp on EFL students' Vocabulary Learning. 9(1), 23-38.

Bere, A. (2013). Using Mobile Instant Messaging to Leverage Learner Participation and Transform Pedagogy at a South African University of Technology. British Journal of Educational Technology, 44(4), 554-561.

Binti Mistar, I., \& Embi, M. A. (n.d.). Students ' perception of the use of WhatsApp as a learning tool in the ESL classroom. Journal of Education and Social Sciences, 4((6)), 96-104.

Bouhnik, D., Deshen, M., \& Gan, R. (2014). WhatsApp Goes to School: Mobile Instant Messaging between Teachers and Students. 13, 217-231.

Braun, V., Clarke, V., Braun, V., \& Clarke, V. (2008). Using thematic analysis in psychology Using thematic analysis in psychology. 0887(2006).

Dehghan, F., Rezvani, R., \& Fazeli, S. (2017). Social networks and their effectiveness in learning foreign language vocabulary: A comparative study using WhatsApp. CALL-EJ, 18(2), 1-13.

Fathy, S., Said, E., \& Fattah, A. (2015). The Effectiveness of Using WhatsApp Messenger as One of Mobile Learning Techniques to Develop Students , Writing Skills. 6(32), 115-127.

Georgia, C.-P. (2020). Transition to Online Education in Schools during a SARSCoV-2 Coronavirus Transition to Online Education in Schools during a SARSCoV-2 Coronavirus ( COVID-19) Pandemic in Georgia. April. https://doi.org/10.29333/pr/7937

Lauricella, S., \& Kay, R. H. (2013). Exploring the Use of Text and Instant Messaging in Higher Education Classrooms. March 2014, 0-17. https://doi.org/10.3402/rlt.v21i0.19061

Lents, N. H. (2015). Increasing Student-Teacher Interactions at an Urban Commuter Campus through Instant Messaging and Online Office Hours Increasing Student-Teacher Interactions at an Urban Commuter Campus through Instant Messaging and Online Office Hours. January.

Lu, M. (2008). Effectiveness of vocabulary learning via mobile phone. May 2006, 515-525. https://doi.org/10.1111/j.1365-2729.2008.00289.x

Pratama, H., \& Kartikawati, S. (2017). The Effect of WhatsApp Messenger As Mobile Learning Integrated with Group Investigation Method of Learning Achievement. 2(1), 164-173. https://doi.org/10.20961/ijsascs.v2i1.16702

Salam, S., Jianqiu, Z., Pathan, Z. H., \& Lei, W. (n.d.). Strategic barriers in the effective integration of ICT in the public schools of Pakistan. In Proceedings of the 201169-1727 International Conference on Computer Science and Artificial, 169-172.

Stockwell, G. (2008). Investigating Learner Preparedness for and Usage Patterns of Mobile Learning. ReCALL, 20(253-270). https://doi.org/https://doi.org/10.1017/S0958344008000232

Yeboah, J., \& Ewur, G. (2014). The Impact of WhatsApp Messenger Usage on Students Performance in Tertiary Institutions in Ghana. Journal of Education and Practice, 5((6)), 157-164. 